\title{
LII. Twin prisms for polarimeters
}

\section{Professor Silvanus P. Thompson D.Sc.}

To cite this article: Professor Silvanus P. Thompson D.Sc. (1887) LII. Twin prisms for polarimeters, Philosophical Magazine Series 5, 24:150, 397-401, DOI: 10.1080/14786448708628121

To link to this article: http://dx.doi.org/10.1080/14786448708628121

曲 Published online: 29 Apr 2009.

Submit your article to this journal $\pi$

Џ Article views: 3

Q View related articles $\sqsubset$ 
is greater the less the radius of the sphere. Hence, at a given time since consolidation, the rate of rock-folding on the smaller of two planets is to that on the larger in a greater ratio than the surface of the former to the surface of the latter.

6. Nothing can be inferred from this as to the relative heights of individual mountain-ranges on different planets. If, however, at the same periods of their history, the mountains on a small planet be of the same or less average height than on a large one, then the rate of continental evolution on the former must, area for area, be greater than on the latter ; or, cateris paribus, the continents of a small planet encroach upon its ocean-areas more rapidly than do those of a larger one.

Perhaps this may in part account for the possibly advanced state of development of the planet Mars, as indicated by what seem to be its comparatively extensive continents and narrow ocean-beds.

LII. Twin Prisms for Polarimeters. By Professor Silvanus P. Thompson, D.Sc.*

710 explain the points of novelty in the new twin-prisms now exhibited by the author, a brief résumé of some of the recent advances in polarimetry is needed. In the earliest apparatus, dating from the time of Biot, the polarizer was usually a bundle of glass plates, the analyzer a simple doubleimage prism or Nicol prism provided with a divided circle to measure its rotation. With the subsequent substitution of compensators and of spectroscopic apparatus in the analyzing portion of the apparatus, this paper has no concern, inasmuch as the prisms to be described are intended to serve as polarizers only, not as analyzers.

When the polarizer was a mere bundle of plates, or a Nicol prism, producing simple plane-polarized light of approximately homogeneous complaneity all over the visual field of the apparatus, exact measurements of the angle of rotation were not easy, simply because the eye failed, through a certain range of angle, to determine the precise position of the analyzer giving maximum extinction of light. For more exact polarimetry, Soleilt, in 1845 , introduced the biquartz

* Communicated by the author, having been read before Section A of the British Association Meeting at Manchester.

$\dagger$ Comptes Rendus, xx. p. 1805, 1845; xxi. p. 426,1845; xxiv. p. 973, 1847 ; and xxvi. p. $163,1848$. 
plate, and the eye, instead of trying to determine the absolute degree of blackness, had merely to make a comparison between the tints of the two simultaneously visible halves of the visual field. With the same object Pohl*, in 1856, suggested the use of a thin piece of mica covering part of the visual field. This suggestion was improved upon in 1874 by Laurent $\dagger$, who proposed to cover half the polarized field with a half-wave plate of quartz; this construction being known as the saccharimètre à pénombres, or half-shadow polarizer. In the Laurent apparatus, the two balves of the visible field are consequently polarized in planes inclined to one another at an angle dependent on the position given to the half-wave plate.

In 1860 , Jellett $\ddagger$ introduced the ingenious triple image prism, in which, at either side of an ordinary image, are seen two extraordinary images, having their respective planes of polarization inclined at a small angle to one another. Hence, when one of these two images is at maximum extinction, the other will not be quite extinguished; and as a very small angular displacement will greatly affect the relative amounts of light in these two images, the adjustment to equality by the eye gives the exact position of the mean plano of polarization of the two images within a very narrow range. In Jellett's apparatus this prism was used as an analyzer only.

Based upon this idea, Cornu $\S$, in 1873, suggested a prism à pénombres, constructed by Duboscq, consisting of a Nicol prism, which, having been cut in two longitudinally, in a plane at right angles to the balsam-film, and a small wedge ground away, was reunited with balsam, so giving in the two halves of the visible field light polarized in planes at a small angle to one another. In Cornu's apparatus, this divided Nicol prism was to be used as analyzer, with an ordinary simple polarizer. Schmidt and Haensch\|, in 1878, simplified this construction by cutting out the wedge from one half of the Nicol prism only, and again reuniting the parts. Lippich $\uparrow$, in 1882, suggested for the same purpose covering half the polarized field with a smaller polarizing prism rotated

* Wiener Berichte, xxii. p. 492, 1856.

† Journal de Physique (1) iii. p. 183, 1874. See also Dufet in Journal de Physique (2) i. p. 552, 1882.

$\ddagger$ Rep. Brit. Assoc. 1860, ii. p. 13; Proc. Roy. Irish Acad. viii. p. 279, 1863; Trans. Roy. Irish Acad. xxv. p. 371, 1875.

$\S$ Bulletin Soc. Chim. [2] xiv. p. 140.

ii See Landolt, Bericht über die Polarisationsapparate, Berlin, 1880.

Tी Zeitschrift für Instrumentenkunde, ii. p. 176, 1882 ; Wiener Berichte, xci. p. 1059, 1885. 
through a small angle, thereby attaining a similar result, but admitting of adjustment in the angle. He proposed to use square-ended prisms constructed like those described by the author* in 1881, having the balsam-film in a principal plane of section of the crystal, and having the end-faces also principal planes of section. A similar arrangement has been used by von Helmholtz. Righit has proposed a combination of two Nicol prisms laid parallel to one another, with two pairs of plates of parallel-worked glass set $V$-wise to divide, and again reunite side by side the beams traversing the two Nicols. Poynting $\ddagger$ has suggested the use of a shallow cell covering the polarized field and containing a sugar solution, but into which a plate of glass is introduced, so as to diminish, over half the field, the thickness of the interposed solution, and so bring about a small angular difference of displacement of the plane of polarization between the two halves of the field. Another suggestion due to Poynting is to cover the two halves of the field with a quartz plate, of any convenient thickness, but reduced uniformly by a small amount, say 0.1 millim. over one half. Lastly, Pickering $\$$ has suggested the use of a double-image prism, arranged like the prism of a dichroiscope, so as to give two contiguous but oppositelypolarized images of a rectangular aperture placed beyond it. These will appear equally illuminated only when the analyzer is at $45^{\circ}$, or when the illumination of each is half the maximum illumination of either.

In the two forms of twin-prisms that are now exhibited, the angle between the planes of polarization in the two halves of the field of vision is fixed. In the one it is $90^{\circ}$, in the other about $2^{\circ} 30^{\prime}$.

In 1886 the author described some forms of simple polarizing prisms cut for him by Mr. Ahrens on the plan adopted by that clever constructor for the later forms of his triple prisms, the principle of which consists in finding a pair of characteristic planes within the crystal of iceland spar such that they are at right angles with the terminal faces (which are principal planes of section), and so oriented that they pass through the line of intersection made by the terminal faces with the natural faces of cleavage. Prisms made on this plan, which is a mere modification of the plan suggested

* S. P. Thompson, Rep. Brit. Assoc. 1881, ii. p. 563, and Phil. Mag. Nov. 1881, p. 349.

$\dagger$ Repertorium der Physik, xxii. p. 321, 1886.

I See Glazebrook's Physical Optics, p. 409.

\$ Proc. Amer. Acad. "Nay, 1885. 'See also Zeitschrift für Instrumentenkunde, vi. p. 281, 1886. 
by the author in 1881, have several advantages over ordinary Nicol prisms. Their polarized field is more homogeneons, their transverse section is rectangular, their terminal faces are at right angles to the axis of vision; and by the method of construction adopted it is easy to obtain from one piece of spar two identical prisms cut from a single rectangular block. These points are all of advantage for the present purpose, namely, that of perfecting the apparatus for use in precise polarimetry.

Prisms cut on Ahrens's plan also possess another peculiarity ; the terminal faces are, as mentioned above, principal planes of section, but the crystallographic axis lies in these faces at almost exactly $45^{\circ}$ with the rectangular edges. Hence it comes about that, if one of these simple prisms be reversed end for end, while used as either polarizer or analyzer, the dark field is changed to bright field, or vice versâ, the same as if the prism had been rotated about its axis of vision through $90^{\circ}$. This is, of course, not the case with any of the ordinary Nicol, Foucault, or Hartnack prisms. Suppose, then, that two identical prisms, cut as described, are taken, of narrow rectangular cross-section, having the sides of the section in the proportion of $2: 1$. Let them be placed side by side so that, as the light falls through them, the visible juxtaposed fields of vision form the two halves of a square. Let one prism be then reversed end for end. The juxtaposed field of vision would still be a square divided into two halves; but these two halves will be oppositely polarized. Such a twin-prism can be used for polarimetry exactly as the Pickering prism or as these half-shadow combinations, in which there is a fixed angle of $90^{\circ}$ between the planes of polarization of the two halves of the visual field. 'The first twin-prism now exhibited by the author is of this nature.

In the second form of twin-prism, the same mode of construction is followed so far as the cutting of two identical prisms of narrow rectangular section is concerned; but, after the prisms have been cut, a small wedge of about $2^{\circ} 30^{\prime}$ is ground away from the side of one of them, and they are then again juxtaposed, so that there is this amount of angular displacement between the two halves of their joint visual field. In both cases the two prisms are ground together and cemented by balsam, so that the observer sees merely a fine line of junction down the middle of the visual field.

The author considers such constructions superior to that of Righi, because there is much less loss of light by reflexion at oblique surfaces; he also prefers his method to the methods of Laurent and of Poynting, because there is no difference in 
the angular displacement for light of different wave-lengths, as is inevitable where quartz, mica, or sugar is used to produce a rotation in one half of the field. It is preferable to Jellett's, because, in the Jellett prism, not only do the two images of varying intensity, which are to be compared, not lie in juxtaposition to one another, but there is the ordinary image lying between them interfering with the comparison. Lastly, the twin-prisms now described are more easy to construct than the divided Nicol prisms of Cornu and of Schmidt and Haensch.

September, 1887.

LIII. On the Theory of Unipolar Induction. By Prof. E. Endund, Professor of Physics at the Royal Acudemy of Sciences of Sweden*.

\section{$\S 1$.}

TNCREASE or decrease in the intensity of the pole of 1 a magnet produces, in a conductor which is approaching it, an electromotive force tending to create an electric current. The increase or decrease in the distance between the pole and the conductor gives rise to a like force, seeing that the action of the pole increases or diminishes in this case as in the former. The electric currents proceeding from this cause are said in both cases to be due to magneto-electric induction; but it is also possible to produce electric currents by means of a magnetic pole without increasing or decreasing the intensity of the pole, and without increasing or decreasing the distance between the pole and the conductor. It is said, then, that the production of the electric current is due to unipolar induction; an expression which is in no sense appropriate, seeing that the conditions necessary for the production of the first-mentioned currents are not applicable to the production of the second, and that moreover the additional term unipolar is the result of a mode of explaining the origin of the currents mentioned which is actually without meaning. These currents are not produced by induction, in the proper and original meaning of the term, but they appear rather, as will be shown further on, to have a magneto-electric origin-that is to say, to be due to the direct action of the magnet on an electric current. It is chiefly in Germany that the theory of the so-called Unipolar Induction has been developed, and attempts made to defend the theory against objections which have been recently raised against it.

* Translated from a memoir presented to the Academy of Sciences of Sweden on the 9th of March, 1887. Communicated by the Author. 